\title{
The case of 28-year-old female after Senning procedure with persistent atrial flutter and severe triscuspid regurgitation
}

\author{
Joško Bulum ${ }^{1 *}$, Ivan Aladrović ${ }^{1}$, Jadranka Šeparović Hanževački', Darko Anić', \\ Božidar Ferek-Petrićc ${ }^{2}$ Aleksander Ernst', Martina Lovrić Benčić', Blanka Glavaš Konja', \\ Davor Miličić1 \\ ${ }^{1}$ University of Zagreb School of Medicine, University Hospital Centre Zagreb, Zagreb, Croatia \\ ${ }^{2}$ Medtronic CRDM Adriatic, Zagreb, Croatia
}

Transposition of the great vessels (TGA) is a rare condition with incidence of $1: 5,000$. The most common variant is $d$ transposition or complete transposition. Pivotal surgical procedure (Senning, 1957) has dramatically improved survival. However, typical long term complications include pressure overload of the systemic right ventricle with tricuspid regurgitation and atrial arrhythmias. Most of the patients are in NYHA I-II functional status 30 years after the operation but only $40-50 \%$ of them remain in sinus rhythm, while $30 \%$ of patients had minimally one episode of atrial flutter. A 28 year-old female was admitted to our Department in November 2011. When she was 9 months old, she underwent Senning procedure because of d-TGA. She was asymptomatic on beta-blocker until the age of 26 when she experienced palpitations and reduced effort tolerance. In addition, she was planning a pregnancy. Echocardiography showed the dilated and hypertrophic systemic right ventricle with reduced systolic function, and moderate to severe tricuspid regurgitation. Atrial conduits have a normal function. Cardiovascular magnetic resonance imaging showed a right ventricular hypertrophy without signs of fibrosis, and preserved

Received: $11^{\text {th }}$ Apr 2014

*Address for correspondence: Klinički bolnički centar Zagreb, Kišpatićeva 12, HR10000 Zagreb, Croatia.

Phone: +385-1-2367-463

E-mail: jbulum@gmail.com systolic function (EF 48\%). ECG revealed atrial flutter with 4 episodes of wide QRS tachycardia on 24-hours Holter ECG. Amiodarone and ACE inhibitor were introduced with clinical and Holter ECG improvement. Cardiac surgeons were consulted and the conclusion was that pregnancy with current medical therapy and atrial flutter would be too risky. Surgical therapeutic option would be tricuspid valve replacement with biological prosthesis and concomitant surgical AV node ablation with the implantation of epicardial electrodes of permanent pacemaker. The patient was sent to Charite Hospital in Berlin where successful ablation of atrial flutter was performed. However, at three months follow-up, recurrent atrial flutter was revealed both on ECG and Holter ECG. In April 2013, the patient underwent successful tricuspid valve replacement with biological prosthesis implantation followed by surgical AV node ablation and implantation of 3 epicardial electrodes on the right ventricle under TEE guidance in order to avoid cardiac dyssynchrony. Postoperative course was uneventful and the patient was discharged at day 5 . The follow-up after 5 months showed an excellent function of the biological prosthesis in tricuspid position, the patient was asymptomatic and we gave her permission for pregnancy.

KEYWORDS: transposition of great arteries, Senning procedure, atrial flutter, heart failure.

CITATION: Cardiol Croat. 2014;9(5-6):239.

\section{Literature}

1. Moons $P$, Gewillig M, Sluysmans $T$, Verhaaren $H$, Viart $P$, Massin M, Suys B, Budts W, Pasquet $A$, De Wolf $D$, Vliers A. Long term outcome up to 30 years after the Mustard or Senning operation: a nationwide multicentre study in Belgium. Heart. 2004:90:307-13. 